\title{
Anarquia e Conformação das Coisas: algumas observações sobre revolução, história e linguagem em Edmund Burke.
}

Daniel Lago M onteiro

daniel.I.monteiro@ hotmail.com

Universidade de São Paulo, São Paulo, Brasil

resumo 0 presente artigo inicia-se com a análise de uma carta de Edmund Burke de J aneiro de 1790, momento em que o estadista se declarou contrário à Revolução Francesa, para vinculá-la a outros textos do autor nos quais os aspectos orgânico e hereditário da sociedade civil, assim como o papel formador e deformador das palavras na atividade política, são tratados. A segunda parte desse texto consiste na tradução e notas à tradução da referida carta de Janeiro de 1790 .

palavras-chave Edmund Burke; revolução francesa; história; linguagem; forma; deformidade.

I.

A carta de Janeiro de $1790^{1}$, que aqui apresentamos traduzida, registra 0 momento em que o estadista e membro do Partido W hig², Edmund Burke (1729-1797), declarou-se contrário à R evolução Francesa, apresentando alguns dos principais motivos que o levaram a contrapor-se ao "atual estado de coisas na França". A té então, Burke, "um dos oradores públicos mais inspirados da história do governo representativo" (BR O M W ICH , intr. 2000, p. 1), havia se silenciado diante da magnitude do evento histórico de maior importância de seu tempo. Contudo, quando a bancada liberal começou a dar sinais de apoio incondicional aos revolucionários franceses - após os arqui-inimigos e mais influentes representantes do whigism, C harles James Fox eW illiam Pitt3, enaltecerem a R evolução -, para surpresa e decepção do partido, em um discurso 
proferido na Câmara dos Comuns de fevereiro daquele ano, Burke se pronunciou publicamente contrário à $R$ evolução. $A$ renúncia em partiIhar do crescente entusiasmo que tomava conta dos liberais ingleses assumiu sua forma mais contundente nas $R$ eflexões sobre a $R$ evolução em $F$ rança, publicada em novembro do mesmo ano. Com esta obra, o autor afirmava-se como uma das figuras mais importantes e controversas do cenário político europeu de seu tempo e, junto dela, segundo afirmou boa parte dos historiadores, cientistas políticos e homens de Estado, 0 pensamento político conservador ganhou feições novas e Burke o título de pai fundador do 'conservadorismo moderno'. Esta alcunha, por sua vez, tende a obscurecer todo um universo de problemas que dizem respeito a seu pensamento histórico, político, sua linguagem e estilo e, sobretudo, ao contraste entre o Burke 'contra-revolucionário' e o orador que, em mais de trinta anos de carreira política, sempre se posicionara em defesa da liberdade civil, do direito das minorias e em oposição ao abuso de poder. Exemplo disso nota-se na crítica que Burke fez à campanha militar inglesa na A mérica, ou em sua denúncia contra as irregularidades administrativas e as injustiças sociais na Índia deWarren $\mathrm{H}$ astings ${ }^{4}$. $\mathrm{O}$ que havia de tão repugnante na $R$ evolução Francesa que provocara sua revolta e o levara a escrever, nos dizeres de N ovalis acerca das R eflexões, "uma obra revolucionária contra a revolução"? (N OVALIS, 2001, p. 98)

Por mais relevante que seja essa questão, não nos cabe aqui discutir os motivos e os sentidos da reviravolta no pensamento político de Edmund Burke, identificada, primeiramente, pelos seus contemporâneos e, mais tarde, por parte da historiografia moderna através da expressão: “o problema B urke" 5 . C om esta breve apresentação, pretendemos, tão somente, a partir da leitura da carta de Janeiro de 1790 e da mobilização de outros textos do autor, refletir sobre a oposição que ali ele estabelecera entre história e revolução, a qual doravante passará a ser o mote de suas reflexões, bem como alguns dos problemas de linguagem envolvidos nesse embate.

Poucos foram os pensadores, políticos e homens de letras que identificaram com tanta perspicácia e prontidão a R evolução Francesa com um momento único e sem antecedentes na história, tal qual o fez Burke. Se para boa parte dos liberais ingleses a França, ao tomar o poder da monarquia, estava seguindo o caminho aberto pela R evolução Gloriosa de 
1688, Burke, desde o começo, apontava para as diferenças em prinápio entre uma revolução e outra. Pela primeira vez na história, segundo argumenta o orador, um governo era destituído pelo esforço conjugado das forças armadas com teo rias políticas e especulações filosóficas à revelia do passado e da tradição. Se, nas revoluções inglesas do século anterior, os revolucionários tinham os olhos voltados para o passado, pois o que reivindicavam era 0 restabelecimento da autoridade da $M$ agna $C$ arta documento constitucional do século XIII que garantia os limites do poder real e assegurava o caráter misto do governo inglês - , os dirigentes do "novo sistema", a A ssembleia $\mathrm{N}$ acional, precisavam dissolver as formas existentes, fundamentalmente ligadas ao passado, para daí então instaurar o novo. U m dos pilares da tese de B urke contra o pensamento jacobino, 0 qual já aparece na presente carta e que ganhará corpo nos escritos e discursos ulteriores, consiste em desmentir a crença de que isso fosse possível, que se pudesse erguer um sistema político e uma sociedade civil em detrimento de sua história, através da aplicação de uma teoria, pelo uso da violência armada ou pela promulgação de leis. Como dirá Burke nas R eflexões: "podes alterar os nomes. As coisas, de uma forma ou de outra, permanecem" (BU R KE, 1993, p. 142). M as qual o preço a se pagar caso se queira, como na França revolucionária, constranger as coisas aos nomes? Para o autor, a anarquia das coisas e o rompimento com a noção orgânica de sociedade e de história.

Burke defende que o sistema político não é um ramo da autoria, um construto da mente de uns poucos e instruídos homens, supostamente mais espertos ou mais conscientes politicamente. $M$ as, antes, o governo encontra o seu nascedouro naquilo que é natural e próprio ao homem, "animal social" . A autoridade da M agna C arta como instituição política não remonta a este ou àquele indivíduo, ou a grupos de indivíduos. Tampouco teria ela validade alguma caso fosse isolada historicamente e amputada daquilo que a vincula ao passado e ao futuro. Do mesmo modo, como mero conjunto de leis, o poder de influência de um documento tão longínquo e de origens tão incertas seria débil e limitado. Pois, "as leis (ao contrário dos costumes)", diz Burke em A Paz R egicida, "só nos toca aqui e ali, e de vez em quando" (BU R KE, 1999, p. 520). Para ele, a C arta é a expressão do "direcionamento de uma força comum", compartilhada por uma comunidade enquanto depositária de uma 
cultura e tradição. N as R eflexões, em uma passagem bastante conhecida, diz Burke: "[a sociedade] não se torna uma associação apenas entre os que estão vivos, mas entre aqueles que estão vivos, os que estão mortos e os que ainda estão por nascer" (BU R KE, 1993, p. 96). Burke procurou ilustrar esse argumento, bem como 0 aspecto originário e hereditário de toda instituição política, com a metáfora do "ser vivo", que podemos ler com abundância nas R eflexões. Ali o governo é comparado a uma planta, a um corpo, a um todo orgânico em que "nenhuma de suas mudas é estranha à natureza do original" (BU R KE, 1993, p. 31). U m sistema de governo é o desdobramento natural - e, portanto, histórico - de uma sociedade civil com a qual mantém uma relação de interdependência em que se exclui 0 mero nexo causal de um antes e um depois. $\mathrm{N}$ a carta de Janeiro de 1790, essa ideia é expressa pela seguinte frase: "a ostra produzirá a concha que melhor a adéque". Toda organização política tende a uma "forma mais habitual" e, mesmo a completa dissolução do estado atual, pouco pode frente à conformação natural das coisas.

A concepção de sociedade civil como um organismo vivo se contrapõe à outra metáfora, a "máquina política". Burke voltou-se contraria e ferozmente à ideia de que se possa fabricar um novo governo. 0 governo fabricado, na melhor das hipóteses, seria como um autômato, imagem que aparece nas $R$ eflexões para se referir à figura que 0 rei assumira na Assembleia $\mathrm{N}$ acional. Constringido por dispositivos impostos de fora para dentro, o novo governo passa então a ser um corpo cujas partes não possuem mais "uma justa subordinação (...) ao todo de um projeto". D aí a necessidade, como insiste o autor na carta de Janeiro de 1790, de manter a população armada e enfurecida, a fim de estabelecer uma "milícia em considerável serviço permanente". Desarraigado do passado, o novo governo encontra na força física o seu fundamento, e por intermédio dela, e não mais dos sentimentos de encantamento e veneração (" princípios fixos de obediência"), os seus idealizadores conduzem as medidas públicas e incitam na população "o deleite atroz pelo homicídio e a cruel selvageria". "Em um governo como o vosso - diz Burke a D epont nas R eflexões - tudo passa a depender do exército; uma vez que vossa nação destruiu habilmente toda opinião, todo preconceito, e (...) todos os instintos que dão sustentação ao governo civil" (BU R KE, 1993, p. 222). 
Ao dissolver as formas existentes ("o país enquanto estado"), os revolucionários acreditavam estar criando um novo homem: livre de preconceitos, superstições e guiado unicamente por princípios racionais. A aproximação entre o pensamento jacobino e a filosofia da Ilustração é bastante conhecida. 0 próprio Burke das $\mathrm{R}$ eflexões insiste no paralelo e opõe-se radicalmente à friez a "dessa filosofia bárbara" (BU R KE, 1993, p. 77) e à geometriz ação do homem e da sociedade que dela redunda6. Em contraste com a França ilustrada, diz Burke sobre a nação inglesa: "não fomos convertidos ao rousseaunismo; também não somos discípulos de Voltaire (...). O s ateus não são nossos pregadores e nem os loucos nossos legisladores" (BU R KE, 1993, p. 86). C ontudo, na carta de Janeiro de 1790, 0 ataque aos filósofos iluministas aparece bem mais atenuado, ao mesmo tempo em que o autor questiona a validade da vinculação entre alguns dos principais nomes do pensamento ilustrado com os "horrendos feitos" de uma multidão enraivecida: "quem jamais sonhou em ver Voltaire e R ousseau como legisladores?" N esse momento final da carta, traduzida nas linhas que se seguem, encontramos Burke empenhado na atividade da qual, desde muito jovem, lançara mão: o exame crítico do estilo e do pensamento de um autor. Para ele, M ontesquieu, não obstante "enganado pelo espírito sistemático", é um escritor "muito culto e engenhoso"; a elegância da escrita de Voltaire fez com que ele aproximasse, como poucos e tão encantadoramente, "a blasfêmia da obscenidade"; a eloquênda de R ousseau lançou "uma luz forte e incomum" sobre as coisas, feznos ver de outra maneira. Tais sutilezas certamente escaparam aos jacobinos: "certo é que nada do que fizeram fora resultado (de) leituras" e "estivesse M ontesquieu vivo nos tempos de hoje, ele certamente estaria entre os fugitivos de França". E o que dizer ainda do realce conferido pelos filósofos da ilustração às paixões, instintos e sentimentos, frente à razão metafísica e ao dualismo da filosofia cartesiana, como lembra o próprio Burke na $\mathrm{C}$ arta a um membro da A ssembleia $\mathrm{N}$ acional?

$R$ ousseau, por sua vez, parece ser um caso mais complicado. Afinal, não fora ele, antes de Burke, o mais ferrenho crítico dos progressos" desta era não-esclarecida" ? A "retórica poderosa" (BU R KE, 1993, p. 271) de Jean-Jacques denunciara as opressões e mazelas do estado civil e trouxera à vista de seus leitores um mundo de desigualdades e injustiças sociais. "Foi H ume - diz Burke, nas R eflexões - que me revelou" os mistérios da escri- 
ta fulgurante de R ousseau: "aquela espéde de maravilhoso (...) que faz surgir novos e inesperados lances (strokes) na política e na moral" (BU R KE, 1993, pp. 171-172, grifo nosso).

0 poder criador das palavras - para além da remissão às ideias dos sentidos e às distinções entre realidade e ficção - está entre os temas de U ma Investigação Filosófica sobre as 0 rigens de nossas I deias do Sublime e do B elo, obra de juventude de B urke. C ontra as teorias que atribuem clareza e univocidade ao 'signo linguístico' - o gênio gramatical, na expressão de Bento Prado Jr. -, o jovem autor defende uma concepção retórica de linguagem, para a qual as palavras não podem ser isoladas de seu contexto ou dimensão pragmática. Assim, as circunstâncias envolvidas no uso das palavras - "um tom de voz emocionado, um semblante apaixonado, um gesto eloquente" (BUR KE, 1958, p. 175) - contribuem mais do que a 'clareza do conceito' para dar sentido e forma ao 'signo linguístico' e "agir sobre a alma de outrem" (PR AD O JR ., 2008, p. 175).A própria dimensão significativa da palavra é posta em questão, uma vez que os aspectos multívoco e plástico da linguagem impedem a remissão de toda palavra a este ou àquele conteúdo da percepção. Libertas dos contornos claros e definidos, as palavras ganham o estatuto de coisas em seu poder de afecção e de ação cuja riqueza passa a depender da arte daqueles que as manuseiam. Incorporados às palavras, os sentimentos, a imaginação e a "energia de expressão" (BU R KE, 1958, p. 176), o bom escritor, ou orador, remodela as formas existentes. A ssim fez o poeta M ilton com os avatares de satã e as descrições de um mundo anterior à conformação das coisas. A ssim também não estaria fazendo a escrita de R ousseau, ao "produzir revoluções e promulgar leis às nações" ? Este tem, ainda, a vantagem reconhecida por Burke sobre aquele. Pois, se o maravilhoso da mitologia de M ilton, "de gigantes, fadas, magos e heróis", há muito "exauriu a parcela de credulidade que pertencia (à sua) época", R ousseau produziu o próprio maraviIhoso ao mundo moderno: "o maravilhoso da vida, dos costumes, das personagens (charaders) e das situações extraordinárias" (BU R KE, 1993, p. 172, grifo nosso). Para "aqueles que gostariam de preservar as coisas more majorum" e impedir "a anarquia das coisas" - a dissolução do estado civil em sua dimensão orgânica e histórica - , o que lhes resta senão uma retórica igualmente poderosa e sublime, não obstante, com ela, as formas convencionais de escrita e prática políticas tenham de ser remodeladas? 


\section{Destinatário desconhecido [J aneiro de 1790]7}

Sinto em dizer-vos, mas, tal como a questão aparece a mim neste momento, não posso, de modo algum, concordar com vossa opinião quanto ao atual estado de coisas na França; ao menos não antes de ter me informado tão bem a esse respeito quanto vós. Espero que não me considereis incapaz de formar minha opinião sobre os acontecimentos que se passam por aí8 senão a partir daquilo que é veiculado pela imprensa, ainda mais se tratando de um país do qual não se pode conhecer amplamente 0 verdadeiro espírito de muitas de suas transações. $\mathrm{N}$ ão obstante, creio que os jornais ingleses não conduzem a opinião do povo daqui, mas, antes, entendo que eles seguem o fluxo das opiniões (notions) predominantes. Q uanto a mim, li, e com bastante atenção, os documentos oficiais sobre esse assunto e ainda aqueles de igual autenticidade, de seus primeiros esclarecimentos até os mais recentes e representativos das classes mais variadas. As demais coisas que li, em sua grande maioria, refletem a opinião daqueles que vêm desempenhando um papel importante na formação e na conduta das medidas públicas. Penso que uma grande parte dos eventos mais decisivos não foi disputada como se disputam fatos, ainda que, como de costume, possam ter tido disputas quanto às suas origens e tendências. Ao comparar o evento como um todo, a partir dos documentos públicos, com aquilo que se pode distinguir do espírito (temper) geral do povo francês, estou de pleno acordo convosco de que seja pouco provável o restabelecimento da autoridade do antigo governo. Q uisesse o rei fugir de seu palácio - onde é hoje mantido, na verdade, como prisioneiro - para aonde ele iria com sua esposa e quase toda a família real? $\mathrm{N}$ a França, toda cidade é uma Paris. $\mathrm{N}$ ão vejo nenhum modo pelo qual uma segunda revolução possa ser consumada. A única chance de isso ocorrer parece advir inteiramente da extrema instabilidade de toda espécie de poder e do caráter incerto de todo tipo de especulação. Q uanto a isso, estamos de acordo, mas, quanto à maioria das circunstâncias particulares, não posso de modo algum assentir convosco. Q ue uma polícia tenha sido estabelecida em Paris, creio de pronto que isso seja verdade. 0 uvi dizer que eles têm um exército de seis mil homens, obviamente sob os seus cuidados. Eles também têm uma milícia em considerável serviço permanente e o número desta milícia 
pode aumentar de maneira quase irrestrita e sob qualquer exigência. Somente eles possuem os meios para preservar a paz, e uma vez que já obtiveram seus fins, esta deve ser a tendência. U ma total anarquia das coisas é uma autodestruição. M as, se doravante forem necessários aqueles meios que foram outrora perseguidos para realizar os mesmos fins, não há dúvidas de que o deleite atroz pelo homicídio e a cruel selvageria serão novamente reavivados. Se alguns daqueles horrendos feitos, que certamente não chegaram desfigurados até nós, foram decretos de governantes, o que podemos esperar de uma população armada por tais governantes? $\mathrm{O} u$ ainda (o que pode bem ser o caso), e se na realidade não houver nenhum governante e, ao invés dos líderes conduzirem o povo, não estariam aqueles sendo por este conduzidos; e se o exército for antes composto por homens que não têm nenhum princípio fixo de obediência, mas que se reuniram apenas pelo predomínio de alguma inclinação geral; quem poderá considerar-se a salvo em meio a uma população tão furiosa e insensata? Quanto à destruição da Bastilha, que vós mencionastes, sabemos não se tratar de algo de grande relevância. N ão há dúvidas de que a Bastilha foi concebida para ser uma fortaleza e é bem provável que ela cumprisse essa função quando fora construída. M as seria ridículo entendê-la como tal nos últimos tempos. Enquanto uma prisão, ela já não tinha mais a menor importânciå9. R ogai por despotismo e não vos faltará as prisões do despotismo, bem como não faltará lamparinas à fúria da democracia... ${ }^{10}$

Sob todos os aspectos, o novo sistema é a realização humana mais precária e mal-acabada que conheço. Confesso não encontrar nele nenhum princípio de coerência, de cooperação, ou uma justa subordinação das partes ao todo de um projeto, nem a menor aptidão às condições e exigências do estado ao qual ele se aplica e nem mesmo qualquer coisa devidamente concebida (well imagined) para a formação, a provisão ou o direcionamento de uma força comum. É justamente o contrário, me parece. C reio que ele traz consigo os próprios indícios da ignorância incurável desta era não esclarecida; ele é o menos qualificado dos sistemas para o exercício da legislação que talvez já tenha existido desde o surgimento da sociedade civil...

0 homem é um animal social11. Ele gradativamente se acomoda a al guma conveniência adequada à sua disposição natural. I sso que hoje nos 
parece estranho poderá, com o tempo, assumir uma forma mais habitual. Por fim, a ostra produzirá a concha que melhor a adéque12. Peço-vos desculpas por ter me alongado em pensamentos sobre um tema que evidentemente fora tão pouco refletido pelos seus criadores. N ão posso concordar convosco de que muito foi feito pela Assembleia. Pelo contrário, muito foi desfeito por ela. 0 país enquanto Estado foi completamente dissolvido de tal modo que vos posso assegurar haver poucos antifrancófonos aqui que não sintam algum grau de piedade diante da deplorável visão de destruição da França. Confesso que, antes de ter visto com meus próprios olhos, era incapaz de conceber como um homem pode demonstrar publicamente tão pouca misericórdia para com o seu próprio país.

D issestes, meu caro senhor, que eles leram M ontesquieu - não creio que isso seja possível; ou, se o leram, não o compreenderam. Por vezes, Montesquieu é um autor obscuro; outras, enganado pelo espírito sistemático; mas, no todo, ele é um escritor muito culto e engenhoso e, em alguns momentos, um pensador bastante profundo. C erto é que nada do que fizeram fora resultado de sua leitura. Estivesse $M$ ontesquieu vivo nos tempos de hoje, ele certamente estaria entre os fugitivos de França. Q uanto aos outros autores de que falastes, creio terem influenciado os dirigentes do atual sistema. Tal mestre, tal discípulo. $M$ as, quem jamais sonhou em verVoltaire e $\mathrm{R}$ ousseau como legisladores? 0 primeiro possui o mérito de escrever agradavelmente bem, e ninguém antes dele uniu com tanta proeza a blasfêmia à obscenidade. Q uanto ao outro, estou quase certo de sua perturbação mental. Entretanto, ele viu as coisas sob uma luz forte e incomum, além de ter sido um homem bastante eloquente. - M as isso é tudo! - Há muito li o Contrato Sodial. Poucos foram os traços que tal obra deixou em minha mente13. C onsiderei-a uma realização de pouco ou nenhum mérito; menos ainda pude imaginar que ela viesse a produzir revoluções e promulgar leis a nações. $M$ as, ao que parece, é isso que recentemente ela vem fazendo. Também vejo aqui algumas pessoas dispostas a tornarem-se discípulos de Voltaire e R ousseau, para então reformar o nosso Estado segundo o modelo francês. E elas já se mobilizaram. Está mais do que na hora daqueles que gostariam de preservar as coisas more majorum ${ }^{14}$ passarem a dar mais atenção a tais pessoas. 


\section{0}

${ }^{1}$ As citações da carta serão feitas entre aspas e sem referência à paginação.Ver nota 7, com as informações sobre a edição utilizada para esta tradução.

2 N ome do partido liberal inglês de fins do século XVII até meados do XIX. Em oposição aos Tories, ou partido conservador, os W higs defendiam a monarquia constitucional e a supremacia do parlamento sobre o monarca.

3 Charles James Fox (1749-1806), assim como Burke, membro da ala radical do partido W hig, ligado ao M arquês de R ockingham; W illiam Pitt, o jovem, (1759-1806), Primeiro M inistro entre os anos de 1783-1806, costumava se auto-referir como independente de posições partidárias.

${ }^{4}$ Warren H astings (1732-1818), primeiro Governador Geral da Índia. Entre os anos de 178795, Burke moveu um impeachment contra o governo de Hastings. Terminando, porém, com a absolvição do governador.

5 Para uma discussão mais abrangente do que foi o "problema Burke" na historiografia moderna, ver o texto de M odesto Florenzano "Burke: 'A M an for All Seasons'". R evista Brasileira de H istória, São Paulo, AM PU H / Ed. U nijuí, vol. 17, n.33, 1997, pp. 32-69.

$6 \mathrm{~N}$ as R eflexões, os nomes de alguns dos principais colaboradores da E ncidopédia aparecem indiscriminadamente ao lado dos representantes da A ssembleia $\mathrm{N}$ acional. Tanto um quanto 0 outro, segundo o autor, são expressões da "era esclarecida", a qual se refere, freqüentemente, em tom de censura e de escárnio.

7 o destinatário da carta permanece desconhecido. Porém, segundo a opinião de Alfred Cobban - estudioso do autor e editor do sexto volume de $T$ he $C$ orrespondence of $E$ dmund $B$ urke, de onde extraímos o texto aqui traduzido -, é possível que se trate do correspondente de Burke na França C harles-Jean-François D epont, o mesmo a quem, meses mais tarde, 0 autor enviará a extensa carta que compõe as $R$ eflexões sobre a $R$ evolução em $F$ rança. $O$ uso recorrente na carta do advérbio de lugar, 'aqui' ou 'daqui', confirma a hipótese de um destinatário estrangeiro. M as C obban não rejeita a possibilidade da carta ter sido enviada a um correspondente inglês, destacando a possibilidade de este ser Thomas Paine, colega de Burke e futuro adversário, uma vez que as primeiras linhas do texto respondem à pergunta que encerra a carta de Paine a Burke de 17 de janeiro de 1790. A tradução segue a edição: T he C orrespondence of E dmund B urke, vol.VI, July 1789 - D ecember 1791, C ambridge U niversity Press, C hicago, Illinois, 1967 (pp. 78-81). G ostaria de expressar meus sinceros agradecimentos ao Prof. Dr. Pedro Paulo Garrido Pimenta por ter chamado a minha atenção para esta carta de Burke.

$8 \mathrm{~N}$ o original, there. $\mathrm{O}$ advérbio em inglês é usado para indicar posição de lugar. C ontudo, ao contrário dos advérbios aí e lá, em português, there não determina o grau de proximidade da pessoa a quem se fala. Desse modo, permanece a ambigüidade quanto ao local em que se encontra o interlocutor de Burke, segundo o que foi dito na nota anterior. Por fim, optei por traduzir there por aí.

9 À quela altura, apenas sete pessoas eram mantidas prisioneiras na Bastilha. A ntes mesmo da revolução, havia uma proposta do governo francês de demolir o edifício.

10 Segundo o editor das Correspondências, Burke, nesta passagem, alude ao uso que os revolucionários faziam dos suportes de lamparinas como lanças. 
$11 \mathrm{Em}$ inglês, gregarious.

12 No original "T he fish will at length make a shell which will fit him". A palavra fish é comumente traduzida para o português por 'peixe'. Contudo, ver vox fish in The 0 xford E nglish D ictionary, 2004, vol.V, p. 969, col. 3: "In popular language, any animal living exclusively in the water; primarily denoting vertebrate animals (... ); but extended to include various cetaceans, crustaceans, molluscs, etc." Vale lembrar ainda que a palavra ostra corresponde, em inglês, a shellfish. Literalmente, o peixe concha, ou o peixe que produz uma concha.

$13 \mathrm{~N}$ os anos de 1759 e 1762, como editor do A nnual R egister, Burke expressou seu interesse por $\mathrm{R}$ ousseau ao publicar resenhas críticas a duas obras do autor genebrino: $\mathrm{C}$ arta a D 'A lembert e E mílio.

${ }^{14}$ Expressão latina que significa: "segundo o costume de nossos ancestrais".

\section{Referências bibliográficas}

BUR KE, E. 1958. A Philosophical Enquiry into the 0 rigins o four I deas of the Sublime and B eautiful. Ed. by JamesT. Boulton. London: U niversity of $\mathrm{N}$ otre Dame Press.

. 1967. T he C orrespondence of $E$ dmund Burke.VolumeVI July 1789 - December 1791. Ed. by A. C obban and R. A. Smith. C ambridge: At the U niversity Press.

1993. $R$ eflections on the $R$ evolution in $F$ rance $\& L$ etter to a $M$ ember of the $\mathrm{N}$ ational A ssembly. Ed. by L. G. M itchell. O xford: U niversity Press. . 1999. L etter on a R egicide Peace. In: K ramnick, I. T he Portable $\mathrm{E}$ dmund B urke. $\mathrm{H}$ armondsworth: Penguin Books. . 2000. 0 n E mpire, Liberty, and R eform. In: Bromwich, D. Speeches and Letters: E dmund Burke. $\mathrm{N}$ ew haven $\&$ London:Yale U niversity Press.

LO CK, F. P. 2010. B urke's R eflexions on the R evolution in F rance. London: $\mathrm{R}$ outledge.

N O VALIS. 2001. Pólen: fragmentos, diálogos, monólogos. Tradução, apresentação e notas R ubens R odriguesTorres Filho. São Paulo: Iluminuras. 
FLOR EN ZAN O, M . 1997. "Burke: 'A M an for All Seasons'". R evista B rasileira de H istória, São Paulo, AM PU H / Ed. U nijuí, vol. 17, n.33, 1997, pp. 32-69.

PR AD O JR ., B. 2008. A R etórica de R ousseau e outros ensaios. São Paulo: Cosacnaify. 